\title{
Ejection Fraction Derived by Noninvasive Modalities Versus Left Ventricular Angiographic Determination
}

\author{
Tahir Tak, MD, PhD
}

[See related article pp. 75 - 82]

Keywords:

Angiography;

Echocardiography;

Left ventricular dysfunction;

Single-photon emission-

computed tomography

Reprint Requests:

Tahir Tak, MD, PhD

Division of Cardiology

University of North Texas

Health Science Center at Fort Worth

855 Montgomery Street

Fort Worth, TX 76107

Tel: 8|7-735-54||

Fax: 817-735-2673

Email: ttak@hsc.unt.edu
$\mathrm{S}$

everal studies have examined the correlation and agreement between noninvasive measurement of ejection fraction (EF) and that derived with left ventricular (LV) angiography. ${ }^{1-4}$ The noninvasive modalities include echocardiography, radionuclide methods, and magnetic resonance imaging. ${ }^{5}$ Echocardiography has been widely used for the evaluation of EF as it is readily available and relatively less expensive than other techniques. M-mode derivations of EF are wrought with errors in patients with technically difficult studies and regional wall motion abnormalities. Simpson's biplane method is nearly reliable, but again is highly dependent on good endocardial border definition. ${ }^{6}$ Although quantitative echocardiography methods are available, visual estimation is known to provide good information to experienced echocardiographers. ${ }^{7}$ Intracardiac opacification (contrast) agents are now being used more frequently and allow better visualization of LV cavity and endocardial boundaries. ${ }^{3}$

In this issue of Clinical Medicine $\&$ Research, Habash-Bseiso et al. ${ }^{8}$ present a retrospective analysis of determination of EF in 534 patients from a single institution who had undergone LV angiography, echocardiography, and nuclear perfusion imaging. They excluded patients who had testing occurring more than 30 days apart. For echocardiography, Simpson's two-dimensional methodology was utilized for deriving left ventricular ejection fraction (LVEF). This method is most helpful for obtaining LV volumes when the LV geometry is distorted. ${ }^{6}$ Radionuclide determination of EF was performed with a single-dose of technetium-99m Sestamibi (Cardiolite). LV angiography was acquired by the single plane method. The endocardial borders of the left ventricle were traced manually by carefully outlining the ventricular silhouette and then converting to area.

Combined LV angiography and echocardiography studies were performed on 202 patients. Similarly, combined single photon emission computed tomography (SPECT) studies and echocardiographic studies were performed on 201 patients. For both groups, studies were performed within 1 month of each other. The results, showing that LVEFs obtained by echocardiography were significantly lower than those obtained by angiography, were consistent with a previous report. ${ }^{9}$ The correlation coefficient was significant $(\mathrm{r}=0.70$, $P<0.0001$ ). When comparing SPECT to LV angiography, the correlation coefficient was also significant $(\mathrm{r}=0.69, P<0.0001)$. 
The LVEFs obtained by SPECT were significantly lower than that obtained by echocardiography, which has also been reported in the literature. ${ }^{10}$ Based on their findings, the authors have proposed the following regression equations for estimation of angiographic LVEFs by either noninvasive technique:

\section{LVEF angiography $=0.66 \times$ LVEF SPECT $+24 \%$ \\ LVEF angiography $=0.73 \times$ LVEF echocardiography $+18 \%$}

The results of previous studies suggest that EF measurements by various technologies are not interchangeable. 5 Magnetic resonance imaging is thought to provide superior imaging quality and may provide a more accurate assessment of EF. ${ }^{11}$ However, this modality is still relatively expensive and not routinely available. Van Royen et al. ${ }^{1}$ have compared LVEF by visual estimation with quantitated equilibrium radionuclide angiography. The correlation of LVEF determined by both methods was good $(r=0.81$, standard error of estimate [SEE] 3.5), but with substantial differences in individual patients.

The question arises as to what modalities should be used routinely to get a fairly accurate and reproducible measure of EF. How should we proceed in clinical practice? The findings of Habash-Bseiso et al., 8 if confirmed by larger prospective trials, may lead to a more widespread use of such regression equations when comparing one technique to the other.

With technological advances and availability of automated edge (border) detection software, intracardiac opacification (contrast) agents for delineation of the LV cavity, and 3-dimensional imaging, the discrepancy between the invasive and noninvasive derived EFs by echocardiography will likely be further narrowed. The same is also true of other noninvasive techniques, which continue to evolve at a rapid pace. Nuclear imaging continues to make strong advances and, like echocardiography, is utilized extensively for evaluation of coronary artery disease and determination of LVEF. At present other noninvasive modalities like magnetic resonance imaging, although promising and accurate, are not yet cost-effective and, thus, are limited largely to research centers.

In practical terms, perhaps the more important question would be: which technique is more accurate and reproducible and should, therefore, be considered as the "gold standard"? Herein lies the greatest challenge of our time - we will inevitably need large prospective trials to address this issue. However, one should be mindful that each technique, whether invasive or noninvasive, is quite unique and, as such, has individual strengths and limitations. The concept of a "gold standard", in this regard, may need to be revisited or redefined. Realistically, however, the choice of a particular technique in clinical practice is often governed by the availability of local resources. Therefore, the important practical issue may not be which technique is best, but rather, which technique is available at a particular institution and possesses reasonable accuracy and reproducibility. The use of regression equations to compare various modalities, thus, may become more meaningful in the future.

\section{References}

1. van Royen N, Jaffe CC, Krumholz HM, Johnson KM, Lynch PJ, Natale D, Atkinson P, Deman P, Wackers FJ. Comparison and reproducibility of visual echocardiographic and quantitative radionuclide left ventricular ejection fractions. Am J Cardiol 1996;77:843-850.

2. Albrechtsson U, Eskilsson J, Lomsky M, Stubbe I, Svensson SE, Tylen U. Comparison of left ventricular ejection fraction assessed by radionuclide angiocardiography, echocardiography and contrast angiocardiography. Acta Med Scand 1982;211:147-152.

3. Hoffmann R, von Bardeleben S, ten Cate F, Borges AC, Kasprzak J, Firschke C, Lafitte S, Al-Saadi N, Kuntz-Hehner $\mathrm{S}$, Engelhardt M, Becher H, Vanoverschelde JL. Assessment of systolic left ventricular function: a multi-centre comparison of cineventriculography, cardiac magnetic resonance imaging, unenhanced and contrast-enhanced echocardiography. Eur Heart J 2005;26:607-616.

4. Baran AO, Rogal GJ, Nanda NC. Ejection fraction determination without planimetry by two-dimensional echocardiography: a new method. J Am Coll Cardiol 1983;1:1471-1478.

5. Bellenger NG, Burgess MI, Ray SG, Lahiri A, Coats AJ, Cleland JG, Pennell DJ. Comparison of left ventricular ejection fraction and volumes in heart failure by echocardiography, radionuclide ventriculography and cardiovascular magnetic resonance; are they interchangeable? Eur Heart J 2000;21:1387-1396.

6. van 't Hof AW, Schipper CW, Gerritsen JG, Reiffers S, Hoorntje JC. Comparison of radionuclide angiography with three echocardiographic parameters of left ventricular function in patients after myocardial infarction. Int J Card Imaging 1998;14:413-418.

7. Rich S, Sheikh A, Gallastegui J, Kondos GT, Mason T, Lam W. Determination of left ventricular ejection fraction by visual estimation during real-time two-dimensional echocardiography. Am Heart J 1982;104:603-606.

8. Habash-Bseiso DE, Rokey R, Berger CJ, Weier AW, Chyou PH. Accuracy of noninvasive ejection fraction measurement in a large community-based clinic. Clinical Medicine \& Research 2005;3:75-82.

9. Kondo C, Fukushima K, Kusakabe K. Measurement of left ventricular volumes and ejection fraction by quantitative gated SPET, contrast ventriculography and magnetic resonance imaging: a meta-analysis. Eur J Nucl Med Mol Imaging 2003;30:851-858.

10. Williams KA, Taillon LA. Left ventricular function in patients with coronary artery disease assessed by gated tomographic myocardial perfusion images. Comparison with assessment by contrast ventriculography and first-pass radionuclide angiography. J Am Coll Cardiol 1996;27:173-181.

11. Van Rossum AC, Visser FC, Sprenger M, Van Eenige MJ, Valk J, Roos JP. Evaluation of magnetic resonance imaging for determination of left ventricular ejection fraction and comparison with angiography. Am J Cardiol 1988;62:628-633.

\section{Author Affiliation}

Tahir Tak, MD, PhD, Professor of Medicine, Division of Cardiology, University of North Texas Health Science Center, Fort Worth, Texas. 